\title{
Impact of Light-Induced Degradation on the Performance of Multijunction Thin-Film Silicon-Based Photoelectrochemical Water- Splitting Devices
}

\author{
Félix Urbain, ${ }^{* \dagger}$ Vladimir Smirnov, Jan-Philipp Becker, and Friedhelm Finger \\ IEK5 - Photovoltaik, Forschungszentrum Jülich, 52425 Jülich, Germany
}

Supporting Information

ABSTRACT: The impact of light-induced degradation (LID) of silicon photoelectrodes on the solar-to-hydrogen efficiency of photoelectrochemical (PEC) devices is investigated. To evaluate the effect, stabilized state-of-the-art thin-film silicon solar cells (after $1000 \mathrm{~h}$ of light soaking) were used as photocathodes in photovoltaic-electrochemical (PV-EC) device assemblies and their performances were compared to the performances of the initial solar-cell-based PV-EC devices. A wide range of photoelectrode configurations (tandem, triple, quadruple) was addressed. With regard to the widespread use
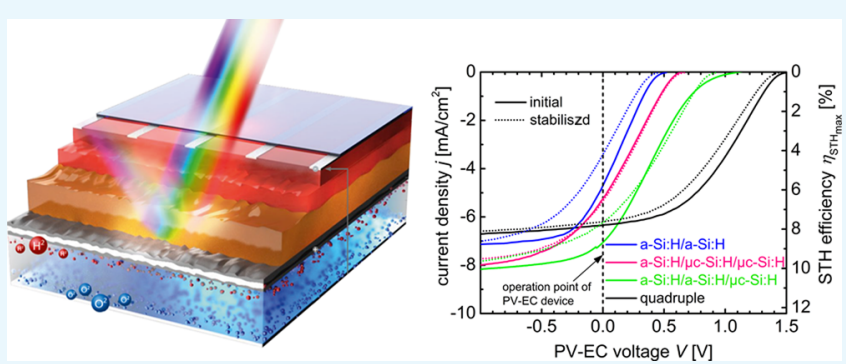
of multijunction-based photoelectrodes in the literature, the results presented herein will have a high impact and may serve as guidelines for the design of photovoltaic devices particularly tailored for PEC applications, with high stabilities and efficiencies. It is shown that LID affects the performances of PV and PV-EC devices in different ways and strongly depends on the photovoltage of the applied solar cell.

\section{INTRODUCTION}

Light-induced hydrogen production using the sun as the only source of energy is particularly suited to contribute to meeting the world's energy needs now and in the years to come. ${ }^{1}$ The application of multijunction thin-film silicon solar cells as photoelectrodes in integrated photoelectrochemical (PEC) devices is a promising approach to efficiently split water into its constituents and thus to generate hydrogen. ${ }^{2-4}$ However, so far, relatively little attention has been paid to the effect of lightinduced degradation (LID) of thin-film silicon photoelectrodes in water-splitting devices. From the pure photovoltaic (PV) application, it is very well known that after prolonged illumination (up to $1000 \mathrm{~h}$ ), LID negatively affects the device performance in single and multijunction solar cells; thus, this needs to be taken into account. ${ }^{5,6}$ Considering the growing interest in the use of thin-film silicon photoelectrodes for water splitting, ${ }^{7-9,2}$ it is vital to address the effect of LID also for PEC applications. We recently studied the effect of LID for quadruple-junction-based photocathodes ${ }^{10,11}$ and demonstrated that the effect of LID on the device efficiency is less pronounced in the PEC configuration compared to that in the PV configuration.

The present study expands beyond this finding and evaluates the effect of LID on the entire range of multijunction photocathodes suitable for bias-free water splitting. Both PV and PEC configurations utilizing tandem-, triple-, and quadruple-junction solar cells are addressed.

The thin-film silicon solar cells were utilized in integrated photovoltaic-electrochemical (PV-EC) solar water-splitting device assemblies, as depicted in Figure 1. Following the taxonomy proposed by Nielander et al., ${ }^{12}$ this device configuration is classified as $P V$-biased electrosynthetic cell and allows for a number of important advantages compared with other device configurations. ${ }^{13,14}$ The impact of LID on the PEC device performance, that is, the solar-to-hydrogen (STH) efficiency, was evaluated in the initial and stabilized (after 1000 $\mathrm{h}$ of light soaking) states of the photocathodes in the PV-EC devices. The obtained results describe to what extent the LID of thin-film silicon-based photoelectrodes prepared in various configurations impact the performance of PV-EC devices.

The tandem- (a-Si:H/a-Si:H), triple- (a-Si:H/a-Si:H/ $\mu \mathrm{c}-\mathrm{Si}: \mathrm{H}$ and $\mathrm{a}-\mathrm{Si}: \mathrm{H} / \mu \mathrm{c}-\mathrm{Si}: \mathrm{H} / \mu \mathrm{c}-\mathrm{Si}: \mathrm{H})$, and quadruple- (a-Si:H/a-Si:H/ $\mu \mathrm{c}-\mathrm{Si}: \mathrm{H} / \mu \mathrm{c}-\mathrm{Si}: \mathrm{H})$ junction solar cells used in this study were developed according to the particular requirements for watersplitting applications, which has been described elsewhere., ${ }^{2,15}$ The cells provide a broad range of photovoltages, ranging from $1.9 \mathrm{~V}$ for the tandem solar cells up to $2.8 \mathrm{~V}$ for the quadruplejunction solar cells.

\section{RESULTS AND DISCUSSION}

Figure 2 displays the impact of LID on the absolute (a) and normalized (b) photovoltaic conversion efficiencies, $\eta_{\mathrm{PV}}$, at degradation times of $1000 \mathrm{~h}$ for tandem-, triple, and quadruplejunction solar cells. It is apparent that the quadruple-junction and a-Si:H/ $\mu c-\mathrm{Si}: \mathrm{H} / \mu \mathrm{c}-\mathrm{Si}: \mathrm{H}$ triple-junction solar cells exhibited

Received: September 21, 2016

Accepted: October 20, 2016

Published: November 7, 2016 


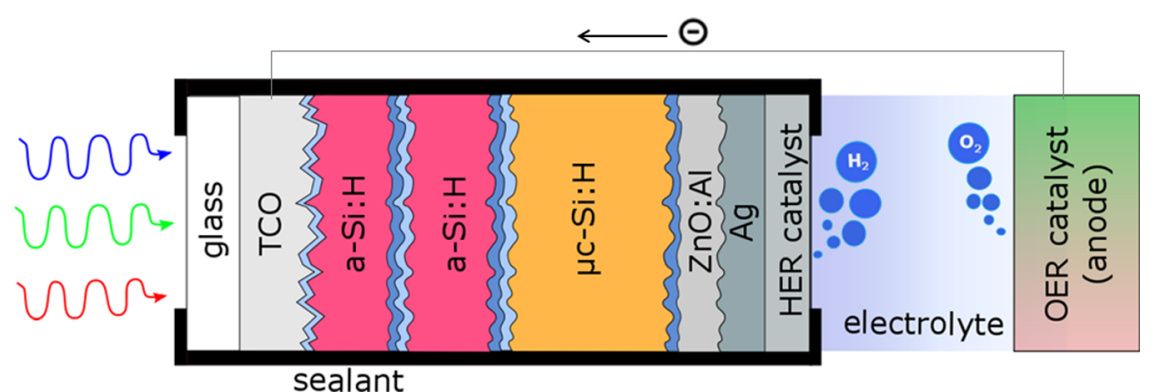

Figure 1. Schematic cross-sectional view of the integrated PV-EC device assembly. The photocathode consists of an a-Si:H/a-Si:H/ $\mu \mathrm{c}-\mathrm{Si}: \mathrm{H}$ triplejunction solar cell with an electrically attached hydrogen evolution reaction (HER) catalyst (here: $\mathrm{Pt}$ ). The photocathode is separated from the oxygen evolution reaction (OER) catalyst (here: the $\mathrm{RuO}_{2}$ electrode) by an electrolyte (here: $0.1 \mathrm{M} \mathrm{KOH}$ ).

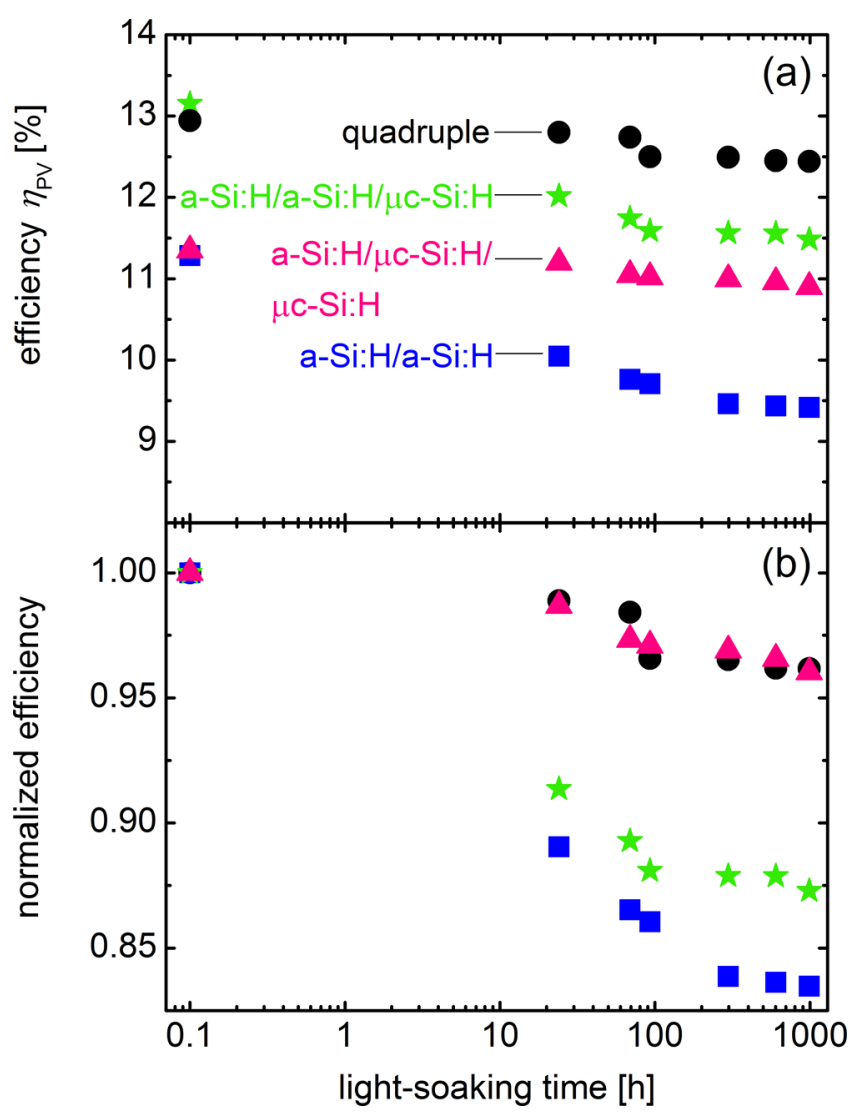

Figure 2. (a) Photovoltaic conversion efficiency, $\eta_{\mathrm{PV}}$, plotted as a function of the light soaking time for tandem-junction, a-Si:H/a-Si:H (blue squares); triple-junction, a-Si:H/ $\mu \mathrm{c}-\mathrm{Si}: \mathrm{H} / \mu \mathrm{c}-\mathrm{Si}: \mathrm{H}$ (pink triangles) and a-Si:H/a-Si:H/ $\mu \mathrm{c}-\mathrm{Si}: \mathrm{H}$ (green stars); and quadruple-junction solar cells (black circles). (b) Photovoltaic conversion efficiency normalized to the initial value as a function of the light soaking time for the tandem-, triple-, and quadruple-junction solar cells.

the highest stabilities against LID, as the relative degradation in efficiency was below $5 \%$ for both these cell types after $1000 \mathrm{~h}$ of illumination. From Figure 2a, it can be seen that the quadruple cell, which provided an initial efficiency of $12.9 \%$, showed the highest stabilized efficiency of $12.4 \%$ among all investigated solar cells. When an antireflection foil was attached to the glass side, an initial efficiency of $13.2 \%$ and a stabilized efficiency of $12.6 \%$ were recorded for this cell (shown in ref 10 ). The conversion efficiencies of the a-Si:H/a-Si:H tandem-junction and a-Si:H/a-Si:H/ $\mu$ c-Si:H triple-junction cells decreased considerably more after light soaking by approximately 15 and $12 \%$, respectively (see Figure $2 \mathrm{~b}$ ).
To give a more detailed picture of the effect of LID on the solar cell performance, Figure $3 \mathrm{a}$ depicts the photocurrent density-voltage curves before and after LID of the solar cells. As can be deduced from this graph, the fill factor (FF) was the most affected photovoltaic parameter for the a-Si:H/a-Si:H tandem-junction and a-Si:H/a-Si:H/ $\mu \mathrm{c}-\mathrm{Si}: \mathrm{H}$ triple-junction solar cells. An absolute decrease in FF by approximately 8$10 \%$ was observed for these two cell types together with a slight decrease in the short-circuit current density, $J_{\text {SC. The exact PV }}$ parameters before and after light soaking can be found in Table S1 of the Supporting Information. For the more stable cell types (relative PV degradation less than 5\%), namely, the a$\mathrm{Si}: \mathrm{H} / \mu \mathrm{c}-\mathrm{Si}: \mathrm{H} / \mu \mathrm{c}-\mathrm{Si}: \mathrm{H}$ triple-junction and the quadruplejunction solar cells, FF and $J_{\mathrm{SC}}$ decreased considerably less compared to that for the other investigated cell types after light soaking (see Figure 3a and Table S1).

The next step consisted of application of the solar cells as photocathodes in the PV-EC device assembly, shown in Figure 1 , before and after the light soaking experiment and comparison of the initial and stabilized STH efficiencies. In Figure 3b, the photocurrent density-voltage characteristics of the initial (solid curves) and stabilized (dotted curves) PV-EC device types are plotted together. From the voltammograms in Figure $3 b$, the $\mathrm{STH}$ efficiency can be approximated by multiplying the current density at $0 \mathrm{~V}$, recorded under illumination, which corresponds to the operation point photocurrent density, $j_{\mathrm{op}}$, of the PV-EC devices, with the thermodynamic potential for water splitting $(1.23 \mathrm{~V})$ and dividing the product by the incident power $(100$ $\left.\mathrm{mW} / \mathrm{cm}^{2}\right)^{2,16}$ When assuming that the total photocurrent density is available for hydrogen production, an estimated maximum achievable STH efficiency, $\eta_{\text {STHmax }}$ can be defined. Among the PV-EC devices based on the initial solar cells, shown in Figure $3 b$, the highest $\eta_{\mathrm{STH} \text { max }}$ of $8.7 \%$ was achieved by the a-Si:H/a-Si:H/ $\mu$ c-Si:H triple-junction-based PV-EC device. The $\eta_{\text {STHmax }}$ values of all devices are listed in Table 1 .

Among the PV-EC devices based on stabilized solar cells (dotted curves in Figure $3 \mathrm{~b}$ ), the a-Si:H/a-Si:H tandemjunction and $\mathrm{Si}: \mathrm{H} / \mathrm{a}-\mathrm{Si}: \mathrm{H} / \mu \mathrm{c}-\mathrm{Si}: \mathrm{H}$ triple-junction devices showed the highest degradation of $j_{\text {op }}$ and thus of the STH efficiency (compare the $\eta_{\text {STHmax }}$ and $\eta_{\text {STHmax,stab }}$ values in Table $1)$. Relative degradations, $\eta_{\mathrm{STH} \text { max,stab }} / \eta_{\mathrm{STH} \text { max }}$ of 0.72 for the tandem-junction-based and 0.88 for the a-Si:H/a-Si:H/ $\mu$ c-Si:H triple-junction-based PV-EC devices were found (see Table 1). The lowest degradation, hence the best stability against LID, was achieved by the a-Si:H/ $\mu \mathrm{c}-\mathrm{Si}: \mathrm{H} / \mu \mathrm{c}-\mathrm{Si}: \mathrm{H}$ solar cell (pink curves in Figure $3 \mathrm{~b}$ ). This device provided an STH efficiency of $6.4 \%$ after $1000 \mathrm{~h}$ of light soaking of the photocathode, which corresponds to an impressively low degradation of less than $1 \%$. 

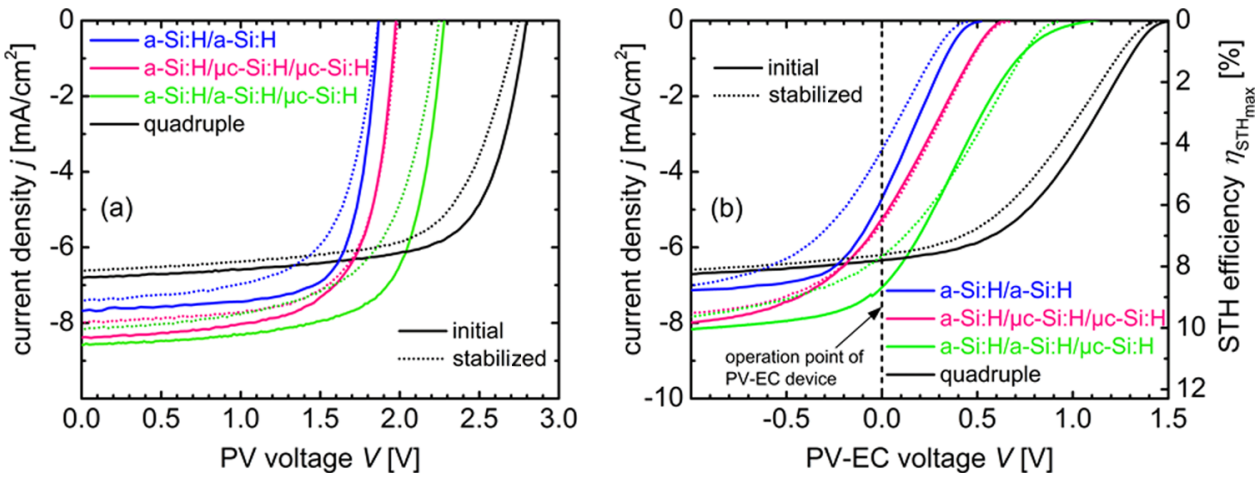

Figure 3. Comparison of the current density-voltage characteristics under illumination of PV (a) and PV-EC devices (b) based on "initial" (solid lines) and light soaked ("stabilized", dotted lines) multijunction solar cells (same as that in Figure 2). For the PV-EC devices, a $100 \mathrm{~nm}$ thick Pt layer was used as the HER catalyst and $\mathrm{RuO}_{2}$ counter electrode, as the OER catalyst. The measurements were conducted in $0.1 \mathrm{M} \mathrm{KOH}$, at a scan rate of $\nu=30 \mathrm{mV} / \mathrm{s}$. The right ordinate in (b) depicts the achievable $\mathrm{STH}$ efficiencies, $\eta_{\mathrm{STH} \text { max }}$ and $\eta_{\mathrm{STH} \text { max }}$ as a function of the photocurrent density at a $0 \mathrm{~V}$ applied bias.

Table 1. Overview of the Initial and Stabilized (after $1000 \mathrm{~h}$ of Light Soaking) STH Efficiencies of Mutijunction-Based PV-EC Devices $^{a}$

\begin{tabular}{lcccc}
\multicolumn{1}{c}{ PV-EC device type } & $\eta_{\text {STHmax }}[\%]$ & $\eta_{\text {STHmax,stab }}[\%]$ & $\eta_{\text {STHmax,stab }} / \eta_{\text {STHmax }}$ & $\eta_{\mathrm{PV}, \text { stab }} / \eta_{\mathrm{PV}}$ \\
a-Si:H/a-Si:H & 5.8 & 4.2 & 0.72 & 0.87 \\
a-Si:H/ $\mu$ c-Si:H/ $\mu \mathrm{c}-\mathrm{Si}: \mathrm{H}$ & 6.5 & 6.4 & 0.99 & 0.97 \\
a-Si:H/a-Si:H/ $\mu$ c-Si:H & 8.7 & 7.6 & 0.87 & 0.87 \\
quadruple & 7.8 & 7.6 & 0.98 & 0.96
\end{tabular}

${ }^{a_{\text {The }}} \eta_{\mathrm{STHmax}}$ and $\eta_{\mathrm{STHmax}, \mathrm{stab}}$ values were evaluated from the $j_{\mathrm{op}}$ values in Figure 3 . The relative degradation of the STH efficiency is also listed and compared to the relative degradation of the photovoltaic efficiency, $\eta_{\mathrm{PV}, \text { stab }} / \eta_{\mathrm{PV}}$, derived from Figure 2 and listed in Table S1.

The quadruple-junction device showed a similar good stability against LID and degraded by only less than $2 \%$, providing a device efficiency, $\eta_{\text {STHmax,stab, }}$ after LID of $7.6 \%$ (black curves in Figure 3b).

To illustrate the differences in the effect of LID on the performances of the PV and PV-EC devices, Table 1 also lists the relative $\mathrm{PV}$ degradation $\left(\eta_{\mathrm{PV} \text {,stab }} / \eta_{\mathrm{PV}}\right)$ in the last column. For all cell types, the relative efficiency degradation was either equal in both the configurations or slightly less pronounced in the PV-EC configuration than that in the PV configuration, except for the a-Si:H/a-Si:H-based device. For the a-Si:H/a$\mathrm{Si}: \mathrm{H}$-based device, the operation point (current density at $0 \mathrm{~V}$ ) lies in the steep slope region of the $j-V$ curve (see Figure $3 b$ ). This is a very critical position for the operation point of the PV-EC device, where a decrease in FF has a stronger and more detrimental effect on $\eta_{\mathrm{STH} \text { max }}$ than that on the pure PV efficiency. In the case of PV devices, the conversion efficiency is defined by the maximum power point (MPP). Thus, $\eta_{\mathrm{PV}}$ is calculated using the voltage and photocurrent density at the MPP (see the $V_{\text {mpp }}$ and $J_{\text {mpp }}$ values in Table S1), irrespective of the location of the MPP. In the case of PV-EC devices, the conversion efficiency, $\eta_{\mathrm{STH}}$, is calculated using the photocurrent density at the operation point ( $0 \mathrm{~V}$ applied bias) and thus strongly depends on the location of the operation point and on FF. As apparent from Figure 3b, the significant decrease in FF in a-Si:H/a-Si:H "shifted" the operation point photocurrent density, $j_{\text {op }}$, to significantly lower values after LID. For this specific example of a tandem PV-EC device, the decrease in $j_{\text {op }}$ due to its unfavorable position had a stronger influence than the degradation of $V_{\mathrm{mpp}}$ and $J_{\mathrm{mpp}}$ in the pure PV configuration, which is why $\eta_{\text {STHmax,stab }} / \eta_{\text {STHmax }}$ was also decreased to a larger extent compared with $\eta_{\mathrm{PV} \text {,stab }} / \eta_{\mathrm{PV}}$.
The a-Si:H/a-Si:H/ $\mu$ c-Si:H solar cell showed an equal PV degradation to that in the a-Si:H/a-Si:H solar cell (see the $\eta_{\mathrm{PV}, \text { stab }} / \eta_{\mathrm{PV}}$ values in Table 1 and the parameters in Table S1). However, its PV-EC degradation was significantly lower (see $\eta_{\mathrm{STHmax}, \mathrm{stab}} / \eta_{\mathrm{STH} \max }$ values of 0.87 vs 0.72 ). Again, this result can be explained by the location of $j_{\text {op }}$. In fact, the operation point of the triple-junction PV-EC device lies at a less critical position (near the MPP of the PV-EC device) compared to that of the a-Si:H/a-Si:H tandem PV-EC device (see Figure $3 \mathrm{~b}$ ). Hence, the higher photovoltage (approximately $2.3 \mathrm{~V}$, see Table $\mathrm{S} 1$ ) of a-Si:H/a-Si:H/ $\mu \mathrm{c}-\mathrm{Si}: \mathrm{H}$ indirectly contributed to the higher stability of the PV-EC device, as it shifted the operation point more in the direction of the MPP (away from the steep slope), at which the degradation of FF has approximately the same effect as that in the PV device.

For the quadruple-based PV-EC device, which provided the highest photovoltage among the investigated devices (approximately $2.8 \mathrm{~V}$, see Table S1), the PV-EC degradation was less pronounced compared with PV degradation (see Table 1). As can be seen in Figure $3 b$, the reduction in the FF of the quadruple-based device after light soaking did not affect the operation point of the PV-EC device significantly. The high photovoltage of the quadruple device shifted its $j_{\text {op }}$ to an uncritical position in the $j-V$ curve (in the "current plateau" region, where the slope of the $j-V$ curve is nearly equal to 0 ), which after light soaking by the photocathode still lies in this region. As already mentioned, in the PV configuration, degradation of FF affects the MPP and thus the conversion efficiency of the solar cell, irrespective of its position. This example therefore proves that a high photovoltage provided by a solar cell clearly contributes to a higher stability against LID in the PV-EC case just by shifting the $j-V$ curve toward more 
positive potentials such that $j_{\mathrm{op}}$ lies in the current plateau region before and after LID.

Although the operation point of the a-Si:H/ $/$ c-Si:H/ $\mu \mathrm{c}-\mathrm{Si}: \mathrm{H}$ PV-EC device lies in the same critical region as that of the tandem PV-EC device (see Figure $3 \mathrm{~b}$ ), this device showed the best stability against LID among all other devices in the PVEC configuration (see Table 1). Hence, for this specific example, the argument of favorable $j_{\text {op }}$ position due to a high photovoltage cannot be applied directly. The impressive stability against LID in the PV-EC and PV configurations originates from the very stable FF and thus from the very stable $j_{\text {op }}$ and MPP values ( $V_{\text {mpp }}$ and $J_{\text {mpp }}$ in Table S1).

\section{EXPERIMENTAL SECTION}

The solar cells were characterized by $j-V$ measurements performed under illumination with a double source sun simulator from Wacom (WXS-140S-super; Wacom Electric Co., Ltd., 541 Tanaka, Fukaya-Shi, Saitama, Japan) under standard test conditions (class A spectrum, $100 \mathrm{~mW} / \mathrm{cm}^{2}, 25$ ${ }^{\circ} \mathrm{C}$ ). LID of the solar cells was performed at $55^{\circ} \mathrm{C}$ under opencircuit conditions, using metal halide lamps with an intensity of $100 \mathrm{~mW} / \mathrm{cm}^{2}$ (class B spectrum).

PEC experiments were performed employing an in-housedesigned PEC cell consisting of a poly(tetrafluoroethylene) cell body on which the working electrode (functionalized solar cell) was mounted with a flange. A solar-cell area of $0.5 \mathrm{~cm}^{2}$ was illuminated through an aperture, using an Oriel LCS-100 solar simulator (Newport Spectra-Physics GmbH, Darmstadt, Germany), providing a simulated AM 1.5G spectrum (100 $\left.\mathrm{mW} / \mathrm{cm}^{2}\right)$. An O-ring $(8 \mathrm{~mm}$ in diameter $)$ defined the geometric contact area of the integrated HER catalyst with the electrolyte (see Figure 1). As the HER catalyst, we chose a $100 \mathrm{~nm}$ thick thermally evaporated Pt layer. ${ }^{17,18}$ The counter electrode was made of a $\mathrm{Ti}$ sheet coated with $\mathrm{RuO}_{2}(12 \mathrm{~g} \mathrm{Ru} /$ $\mathrm{m}^{2}$; Metakem $\mathrm{GmbH}$, Usingen, Germany). The distance between the working and counter electrodes was $2 \mathrm{~cm}$. The employed electrolyte was a $0.1 \mathrm{M} \mathrm{KOH}$ solution, which was prepared with ultrapure deionized water (Millipore, Schwalbach, Germany) and analytical-grade chemicals.

\section{CONCLUSIONS}

In summary, this study investigated the impact of LID on the performance of thin-film silicon-based PV-EC devices for water splitting and revealed the main differences with the degradation behavior of pure PV devices upon LID. For the PV-EC devices, the location of the operation point before and after LID is crucial in particular; in contrast, for the PV devices, only the impact on the MPP is important. It was shown that all tested PV-EC devices except for the tandem-based device showed stabilities against LID that were the same as or higher than those of pure PV cells. These findings could be explained by linking the photovoltages of the solar cells with the degradation of the PV parameters upon LID, in particular FF. At high photovoltages (above $2.3 \mathrm{~V}$ ) degradation of $\mathrm{FF}$ affected the performance of the PV-EC devices equally or less than it affected the performance of PV devices. For photovoltages below $2.3 \mathrm{~V}$, the effect of LID (mostly FF degradation) was more detrimental in the PV-EC case than that in the PV case, mainly because the photovoltage was not high enough to shift the operation point of the PV-EC device close to or above the MPP of the PV-EC device curve, at which the degradation of FF is less pronounced. The highest stability against LID was achieved by the a-Si:H/ $\mu \mathrm{c}-\mathrm{Si}: \mathrm{H} / \mu \mathrm{c}-\mathrm{Si}: \mathrm{H}$ device, which could be explained by an impressively stable FF value upon LID and thus very stable $j_{\text {op }}$ and MPP values.

Finally, it should also be mentioned that compared to the very small reduction in performance for the quadruple- and a$\mathrm{Si}: \mathrm{H} / \mu \mathrm{c}-\mathrm{Si}: \mathrm{H} / \mu \mathrm{c}-\mathrm{Si}: \mathrm{H}$-based PV-EC devices, any degradation due to electrochemical corrosion of the electrodes imposes a much more critical technical challenge, as it can very abruptly degrade and destroy the photoelectrode. In the literature, the typical electrochemical durabilites of silicon-based PEC devices are in the range of less than 100 h. ${ }^{19,20}$ On the other hand, for the a-Si:H/a-Si:H- and a-Si:H/a-Si:H/ $\mu$ c-Si:H-based PV-EC devices, the impact of LID needs to be taken into account, also in the PV-EC configuration. Alternatively, for future applications, the development routes of these two device types could be adapted such that the degraded (or stabilized) performance rather than the initial performance (presented in this study) is optimized, that is, such that their sensitivity to degradation is less pronounced. In any case, the conclusions drawn from this study can be used as guidelines for the design of photovoltaic devices particularly tailored for PEC applications, with high stabilities and efficiencies.

\section{ASSOCIATED CONTENT}

\section{S Supporting Information}

The Supporting Information is available free of charge on the ACS Publications website at DOI: 10.1021/acsomega.6b00259.

Photovoltaic parameters of the multijunction (tandem, triple, and quadruple junctions) thin-film silicon solar cells before (initial) and after $1000 \mathrm{~h}$ of light soaking (stabilized) (Table S1) (PDF)

\section{AUTHOR INFORMATION}

\section{Corresponding Author}

*E-mail: furbain@irec.cat.

\section{Present Address}

†IREC, Catalonia Institute for Energy Research, Jardins de les Dones de Negre 1, 08930 Sant Adrià de Besòs, Barcelona, Spain (F.U.).

\section{Notes}

The authors declare no competing financial interest. E-mail addresses: v.smirnov@fz-juelich.de (V.S.), j.becker@fzjuelich.de (J.B.), and f.finger@fz-juelich.de (F.F.).

\section{ACKNOWLEDGMENTS}

The authors thank S. Moll, A. Lambertz, U. Gerhards, J. Wolff, L. Petter, L. Nießen, and H. Siekmann for their support with sample preparation. The authors gratefully acknowledge the funding by the German Bundesministerium für Bildung und Forschung (BMBF) in the network project Sustainable Hydrogen (FKZ 03X3581B) and the Deutsche Forschungsgemeinschaft (DFG) in the Priority Program 1613: Regeneratively Produced Fuels by Light Driven Water Splitting: Investigation of Involved Elementary Processes and Perspectives of Technologic Implementation.

\section{REFERENCES}

(1) Peter, L. Photoelectrochemical water splitting. A status assessment. Electroanalysis 2015, 27, 864-871.

(2) Urbain, F.; Smirnov, V.; Becker, J.-P.; Lambertz, A.; Yang, F.; Ziegler, J.; Kaiser, B.; Jaegermann, W.; Rau, U.; Finger, F. Multijunction Si photocathodes with tunable photovoltages from 2.0 
$\mathrm{V}$ to $2.8 \mathrm{~V}$ for light induced water splitting. Energy Environ. Sci. 2016, 9, $145-154$

(3) Reece, S. Y.; Hamel, J. A.; Sung, K.; Jarvi, T. D.; Esswein, A. J.; Pijpers, J. J. H.; Nocera, D. G. Wireless Solar Water Splitting Using Silicon-Based Semiconductors and Earth-Abundant Catalysts. Science 2011, 334, 645-648.

(4) Abdi, F. F.; Han, L.; Smets, A. H. M.; Zeman, M.; Dam, B.; van de Krol, R. Efficient solar water splitting by enhanced charge separation in a bismuth vanadate-silicon tandem photoelectrode. Nat. Commun. 2013, 4, No. 2195.

(5) Lambertz, A.; Finger, F.; Schropp, R. E. I.; Rau, U.; Smirnov, V. Preparation and measurement of highly efficient a-Si:H single junction solar cells and the advantages of $\mu \mathrm{c}-\mathrm{SiO}_{\mathrm{x}}: \mathrm{H} n$-layers. Prog. Photovolt: Res. Appl. 2015, 23, 939-948.

(6) Smirnov, V.; Urbain, F.; Lambertz, A.; Finger, F. High stabilized efficiency single and multi-junction thin film silicon solar cells. Energy Procedia 2016, in press.

(7) Licht, S.; Wang, B.; Mukerji, S.; Soga, T.; Umeno, M.; Tributsch, H. Efficient Solar Water Splitting, Exemplified by $\mathrm{RuO}_{2}$-Catalyzed AlGaAs/Si Photoelectrolysis. J. Phys. Chem. B 2000, 104, 8920-8924.

(8) Cristino, V.; Berardi, S.; Caramori, S.; Argazzi, R.; Carli, S.; Meda, L.; Tacca, A.; Bignozzi, C. A. Efficient solar water oxidation using photovoltaic devices functionalized with earth-abundant oxygen evolving catalysts. Phys. Chem. Chem. Phys. 2013, 15, 13083-13092.

(9) Han, L.; Abdi, F. F.; Perez Rodriguez, P.; Dam, B.; van de Krol, R.; Zeman, M.; Smets, A. H. M. Optimization of amorphous silicon double junction solar cells for an efficient photoelectrochemical water splitting device based on a bismuth vanadate photoanode. Phys. Chem. Chem. Phys. 2014, 16, 4220-4229.

(10) Urbain, F.; Smirnov, V.; Becker, J.-P.; Lambertz, A.; Rau, U.; Finger, F. Light-induced degradation of adapted quadruple junction thin film silicon solar cells for photoelectrochemical water splitting. Sol. Energy Mater. Sol. Cells 2016, 145, 142-147.

(11) Lin, Y.; Battaglia, C.; Boccard, M.; Hettick, M.; Yu, Z.; Ballif, C.; Ager, J. W.; Javey, A. Amorphous Si Thin Film Based Photocathodes with High Photovoltage for Efficient Hydrogen Production. Nano Lett. 2013, 13, 5615-5618.

(12) Nielander, A. C.; Shaner, M. R.; Papadantonakis, K. M.; Francis, S. A.; Lewis, N. S. A taxonomy for solar fuels generators. Energy Environ. Sci. 2015, 8, 16-25.

(13) Becker, J.-P.; Urbain, F.; Smirnov, V.; Rau, U.; Ziegler, J.; Kaiser, B.; Jaegermann, W.; Finger, F. Modeling and practical realization of thin film silicon-based integrated solar water splitting devices. Phys. Status Solidi A 2016, 213, 1738-1746.

(14) Bogdanoff, P.; Stellmach, D.; Gabriel, O.; Stannowski, B.; Schlatmann, R.; van de Krol, R.; Fiechter, S. Artificial Leaf for Water Splitting Based on a Triple-Junction Thin-Film Silicon Solar Cell and a PEDOT:PSS/Catalyst Blend. Energy Technol. 2016, 4, 230-241.

(15) Urbain, F.; Wilken, K.; Smirnov, V.; Astakhov, O.; Lambertz, A.; Becker, J.-P.; Rau, U.; Ziegler, J.; Kaiser, B.; Jaegermann, W.; Finger, F. Development of Thin Film Amorphous Silicon Tandem Junction Based Photocathodes Providing High Open-Circuit Voltages for Hydrogen Production. Int. J. Photoenergy 2014, 2014, No. 249317.

(16) Chen, Z.; Jaramillo, T. F.; Deutsch, T. G.; Kleiman-Shwarsctein, A.; Forman, A. J.; Gaillard, N.; Garland, R.; Takanabe, K.; Heske, C.; Sunkara, M.; McFarland, E. W.; Domen, K.; Miller, E. L.; Turner, J. A.; Dinh, H. N. Accelerating materials development for photoelectrochemical hydrogen production: Standards for methods, definitions, and reporting protocols. J. Mater. Res. 2010, 25, 3-16.

(17) Urbain, F.; Smirnov, V.; Becker, J.-P.; Rau, U.; Ziegler, J.; Yang, F.; Kaiser, B.; Jaegermann, W.; Hoch, S.; Blug, M.; Finger, F. Solar water splitting with earth-abundant materials using amorphous silicon photocathodes and $\mathrm{Al} / \mathrm{Ni}$ contacts as hydrogen evolution catalyst. Chem. Phys. Lett. 2015, 638, 25-30.

(18) Urbain, F.; Smirnov, V.; Becker, J.-P.; Rau, U.; Ziegler, J.; Kaiser, B.; Jaegermann, W.; Finger, F. Application and modeling of an integrated amorphous silicon tandem based device for solar water splitting. Sol. Energy Mater. Sol. Cells 2015, 140, 275-280.
(19) Mei, B.; Seger, B.; Pedersen, T.; Malizia, M.; Hansen, O.; Chorkendorff, I.; Vesborg, P. C. K. Protection of p+-n-Si Photoanodes by Sputter-Deposited Ir/IrOx Thin Films. J. Phys. Chem. Lett. 2014, 5, $1948-1952$.

(20) Hu, S.; Shaner, M. R.; Beardslee, J. A.; Lichterman, M.; Brunschwig, B. S.; Lewis, N. S. Amorphous $\mathrm{TiO}_{2}$ coatings stabilize $\mathrm{Si}$, $\mathrm{GaAs}$, and $\mathrm{GaP}$ photoanodes for efficient water oxidation. Science 2014, 344, 1005-1009. 